\title{
Solubility of Tris(hydroxymethyl)aminomethane in Water- Methanol Solvent Mixtures and Medium Effects in the Dissociation of the Protonated Base
}

\author{
Paul Schindler, ${ }^{1}$ R. A. Robinson, ${ }^{2}$ and Roger G. Bates \\ Institute for Materials Research, National Bureau of Standards, Washington, D.C. 20234
}

(November 13, 1967)

\begin{abstract}
The dissociation constant of the protonated form of tris(hydroxymethyl)aminomethane has been measured at $25{ }^{\circ} \mathrm{C}$ in water-methanol solvents containing $30,50,70$, and 90 wt percent methanol by means of potentiometric titrations. The solubility of tris(hydroxymethyl)aminomethane at 15,25 , and $35{ }^{\circ} \mathrm{C}$ in water-methanol solvents containing from 0 to 100 percent methanol has been determined. The results are discussed in terms of free energies of transfer and "medium effects" for hydrochloric acid, tris(hydroxymethyl)aminomethane, and tris(hydroxymethyl)aminomethane hydrochloride.
\end{abstract}

Key Words: Dissociation constant, medium effect, methanol-water solvents, solubility, tris(hydroxymethyl)aminomethane.

\section{Introduction}

The dissociation of an acid of the charge type $\mathrm{A}^{+} \mathrm{B}^{\circ}$, such as the ammonium ion or the protonated form of tris(hydroxymethyl)aminomethane,

$$
\mathrm{BH}^{+}+\mathrm{H}_{2} \mathrm{O} \rightarrow \mathrm{H}_{3} \mathrm{O}^{+}+\mathrm{B},
$$

is a process in which a solvated hydrogen ion and an uncharged basic molecule are produced from a positively charged acid ion. The process in aqueous solution can be characterized by a dissociation constant, ${ }_{\mathrm{w}} K$ :

$$
{ }_{\mathrm{w}} K=\frac{m_{\mathrm{H}^{+}} \cdot m_{\mathrm{B}}}{m_{\mathrm{BH}^{+}}} \cdot{ }_{\mathrm{w}}\left(\frac{\gamma_{\mathrm{H}^{+}} \cdot \gamma_{\mathrm{B}}}{\gamma_{\mathrm{BH}^{+}}}\right)
$$

where ${ }_{w} \gamma$ designates an activity coefficient. For aqueous solutions, it is convenient to refer these activity coefficients to the hypothetical molal standard state in water; thus the activity coefficients approach unity as the aqueous solution becomes more dilute. The subscript $\mathrm{w}$ indicates this choice of the standard state.

In aqueous solution at $25^{\circ} \mathrm{C},-\log _{\mathrm{w}} K$ for the protonated form of tris ${ }^{3}$ has been found $[1,2]^{4}$ to be 8.072 .

\footnotetext{
${ }^{1}$ Guest worker (1965-66), on leave from the University of Bern, Switzerland.

${ }^{2}$ Present address: Department of Chemistry, State University of New York at Binghamton, Binghamton, New York 13901.

${ }^{3}$ It is convenient to use "tris" as an abbreviation for tris(hydroxymethyl)aminomethane. ${ }^{4}$ Figures in brackets indicate the literature references at the end of this paper.
}

The increase in free energy corresponding to the reaction:

$$
\mathrm{BH}^{+}+\mathrm{H}_{2} \mathrm{O} \rightarrow \mathrm{H}_{3} \mathrm{O}^{+}+\mathrm{B}
$$

is:

$$
\Delta_{\mathrm{w}} G^{\circ}=G_{\mathrm{H}^{+}}^{\circ}+G_{\mathrm{B}}^{\circ}-G_{\mathrm{BH}^{+}}^{\circ}=-R T \ln { }_{\mathrm{w}} K,
$$

the free energies of the reactants and the products being measured in their standard states in water. At $25^{\circ} \mathrm{C}$, therefore, $\Delta_{\mathrm{w}} G^{\circ}$ is $46.07 \mathrm{~kJ} \mathrm{~mol}^{-1}$.

If the dissociation constant is determined in another solvent medium, $50 \mathrm{wt}$ percent water-methanol, for example, we have:

$$
{ }_{\mathrm{s}} K=\frac{m_{\mathrm{H}^{+}} \cdot m_{\mathrm{B}}}{m_{\mathrm{BH}^{+}}} \cdot{ }_{\mathrm{s}}\left(\frac{\gamma_{\mathrm{H}^{+}} \cdot \gamma_{\mathrm{B}}}{\gamma_{\mathrm{BH}^{+}}}\right)
$$

where the subscript $\mathrm{s}$ denotes that the activity coefficients are referred to the hypothetical molal standard state in this solvent and approach unity as the solution becomes more dilute without change in the composition of the solvent. It has been found [3] that $-\log$ ${ }_{s} K=7.818$ for the protonated form of tris at $25^{\circ} \mathrm{C}$ in 50 percent methanol. The reaction is:

$$
\mathrm{BH}^{+}+\mathrm{S} \rightarrow \mathrm{SH}^{+}+\mathrm{B}
$$

where $\mathrm{S}$ is a solvent molecule and $\mathrm{SH}^{+}$a solvated hydrogen ion. It is not necessary at this point to dis- 
tinguish between solvation by water and by methanol molecules. The free energy change corresponding to this reaction is $44.62 \mathrm{~kJ} \mathrm{~mol}^{-1}$.

The two processes, one in aqueous solution and the other in 50 percent methanol, can be regarded as a single transfer process

$$
\mathrm{BH}^{+}(\mathrm{s})+\mathrm{H}^{+}(\mathrm{w})+\mathrm{B}(\mathrm{w}) \rightarrow \mathrm{BH}^{+}(\mathrm{w})+\mathrm{H}^{+}(\mathrm{s})+\mathrm{B}(\mathrm{s}),
$$

in which the protonated form of tris is transferred from 50 percent methanol to water and solvated hydrogen ions and tris molecules are transferred in the opposite direction. The change in Gibbs free energy when this process occurs is the difference between the separate free energy changes, or $\Delta_{\mathrm{m}} G^{\circ}=-1.45 \mathrm{~kJ}$ $\mathrm{mol}^{-1}$. The subscript $\mathrm{m}$ is used to indicate that the process is a "medium effect," being the composite effect of transferring three species from one solvent medium to another. As each species is in its standard state in each solvent, the free energy change is not concentration-dependent.

It is convenient to define medium effects for each species separately,

$$
{ }_{\mathrm{m}} G_{i}^{\circ}=R T \ln { }_{\mathrm{m}} \gamma_{i}
$$

so that

$$
\Delta_{\mathrm{m}} G^{\circ}=R T\left(\ln _{\mathrm{m}} \gamma_{\mathrm{B}}+\ln _{\mathrm{m}} \gamma_{\mathrm{H}^{+}}-\ln _{\mathrm{m}_{\mathrm{B}}} \gamma_{\mathrm{BH}^{+}}\right) .
$$

This can be expressed in terms of the $p K$ values:

$$
p_{\mathrm{s}} K-p_{\mathrm{w}} K=\log _{\mathrm{m}} \gamma_{\mathrm{B}}+\log _{\mathrm{m}} \gamma_{\mathrm{H}^{+}}-\log _{\mathrm{m}} \gamma_{\mathrm{BH}^{+}} \text {. }
$$

Hereafter, the terms $\Delta_{\mathrm{m}} G_{i}^{\circ}$ will be termed "free energies of transfer," and the quantities ${ }_{\mathrm{m}} \gamma_{i}$ will be designated "medium effects."

Of these three medium effects, two are concerned with the transfer of charged particles from one solvent to another of different dielectric constant $(\epsilon)$. The Born equation [4]:

$$
G^{e l}=\frac{N e^{2}}{2 \epsilon r}
$$

should, therefore, give at least an approximation to the energy of transfer of an ion from water $\left(\epsilon_{\mathrm{w}}=78.3\right)$ to 50 percent methanol $\left(\epsilon_{\mathrm{s}}=56.3\right)$ :

$$
\Delta_{\mathrm{m}} G_{i}^{\circ} \approx{ }_{\mathrm{s}} G_{i}^{e l}-{ }_{\mathrm{w}} G_{i}^{e l}=\frac{N e^{2}}{2}\left(\frac{1}{\epsilon_{\mathrm{s}}}-\frac{1}{\epsilon_{\mathrm{w}}}\right) \frac{1}{r_{i}}
$$

where the superscript el indicates that the calculation is based on electrostatic considerations alone. The useful application of eq (8) requires that the radius, $r_{i}$, of the ion be known.

The radius of the tris cation was estimated [3] from atom models to be about $4 \AA$ so that, from eq (8), the transfer of a tris cation from water to 50 percent methanol is accompanied by an increase in electrostatic free energy of $0.87 \mathrm{~kJ} \mathrm{~mol}^{-1}$. There is some difficulty in assigning a radius to the solvated hydrogen

\begin{tabular}{|c|c|}
\hline & $\Delta_{m} G^{\circ}$ \\
\hline $\begin{aligned} \mathrm{BH}^{+}(\mathrm{s})+\mathrm{H}^{+}(\mathrm{w})+\mathrm{B}(\mathrm{w}) & \rightarrow \mathrm{BH}^{+}(\mathrm{w})+\mathrm{H}^{+}(\mathrm{s})+\mathrm{B}(\mathrm{s}) \\
\mathrm{H}^{+}(\mathrm{w}) & \rightarrow \\
\mathrm{BH}^{+}(\mathrm{s}) & \rightarrow \mathrm{BH}^{+}(\mathrm{w})\end{aligned}$ & $\begin{array}{l}-1.45 \mathrm{~kJ} \mathrm{~mol}^{-1} \\
+1.24 \mathrm{~kJ} \mathrm{~mol}^{-1} \\
-0.87 \mathrm{~kJ} \mathrm{~mol}^{-1}\end{array}$ \\
\hline
\end{tabular}
ion, but it was estimated [3] that the radius is about
$2.8 \AA$. Hence the transfer of hydrogen ion from water to 50 percent methanol involves an increase of 1.24 $\mathrm{kJ} \mathrm{mol}^{-1}$ in free energy.

We now have

and hence,

$$
\mathrm{B}(\mathrm{w}) \rightarrow \mathrm{B}(\mathrm{s}), \Delta_{\mathrm{m}} G^{\circ}=-1.82 \mathrm{~kJ} \mathrm{~mol}^{-1} .
$$

These results suggest, therefore, that there is a rather large effect, amounting to about $2 \mathrm{~kJ} \mathrm{~mol}^{-1}$, accompanying the transfer of a mole of the neutral tris molecules between water and 50 percent methanol. A more refined treatment by Hepler [5] of a variable dielectric constant in the close vicinity of an ion reinforces the existence of this large transfer energy term for the uncharged base.

In the earlier study [3] of the $p K$ of protonated tris at several temperatures in $50 \mathrm{wt}$ percent methanol, the discrepancy of about $2 \mathrm{~kJ} \mathrm{~mol}^{-1}$ between the calculated and "observed" free energies of dissociation was attributed to a "basicity effect" of the solvent, which was thought to be superimposed on the medium effects calculated from electrostatic considerations alone. This view was taken in the belief that the medium effect of an uncharged species would be so small as to be unable to account for the differences observed between the experimental and calculated free energies of dissociation.

In the present work, the free energy of transfer and the medium effect for the free base have been determined and found to account reasonably well for the "basicity effect" identified in the prior investigation. These conclusions are based on measurements of the solubility of tris in water and in water-methanol solvents and upon a determination of the $p K$ of protonated tris at $25{ }^{\circ} \mathrm{C}$ in $30,50,70$, and 90 wt percent methanol.

\section{Outline of Present Method}

The condition for equilibrium between solid tris and its saturated aqueous solution is:

$$
G(\text { solid })={ }_{\mathrm{w}} G^{\circ}+R T \ln { }_{\mathrm{w}} \gamma \cdot m_{\mathrm{w}},
$$

where $m_{\mathrm{w}}$ is the molality of the saturated solution and ${ }_{w} \gamma$ is the activity coefficient of tris at this molality relative to unity in the standard state in water. The condition for equilibrium between solid tris and its saturated solution in a water-methanol mixture is:

$$
G(\text { solid })={ }_{\mathrm{w}} G^{\circ}+R T \ln { }_{\mathrm{m}} \gamma \cdot{ }_{\mathrm{s}} \gamma \cdot m_{\mathrm{s}},
$$

where $m_{\mathrm{s}}$ is the molality of the saturated solution in the 
mixed solvent and ${ }_{\mathrm{s}} \gamma$ is the activity coefficient of tris at this molality relative to unity in the standard state in the mixed solvent. The proof of eq (10) is given in the appendix to this paper.

It follows from eq (9) and (10) that

$$
\ln { }_{\mathrm{m}} \gamma=\ln m_{\mathrm{w}} / m_{\mathrm{s}}+\ln { }_{\mathrm{w}} \gamma / \mathrm{s} \gamma
$$

and hence that the medium effect, ${ }_{\mathrm{m}} \gamma$, can be obtained from the ratio of the solubilities of tris in water and in the mixed solvent, provided that ${ }_{\mathrm{s}} \gamma /{ }_{\mathrm{w}} \gamma$ is unity. The latter condition will hold to a good approximation if the solute is only slightly soluble in each solvent medium. This would be true, for example, for silver chloride in water and water-methanol mixtures, for in dilute solutions ${ }_{w} \gamma$ and $\gamma \gamma$ are, in the main, expressions of the Debye-Hückel (interionic) forces, and these become more nearly negligible as the solution becomes more dilute. A fortiori, this is true of the ratio $\ln _{\mathrm{w}} \gamma /{ }_{\mathrm{s}} \gamma$. Although tris is uncharged, it is very soluble, especially in water, and it might seem that this condition would not apply. It has, however, been shown [6] that the activity coefficient of tris does not depart much from unity even in concentrated solutions. Similar data are not available for water-methanol mixtures, but there is no reason to believe that $\gamma \gamma$ will depart much from unity in these solvents. As will be shown later, $m_{\mathrm{w}} / m_{\mathrm{s}}$ is large, and it would require values of ${ }_{\mathrm{s}} \gamma$ very different from unity to reduce ${ }_{m} \gamma$ to a negligible quantity. In the absence of any proof that that ${ }_{\mathrm{s}} \gamma$ is markedly different from unity, it will be assumed that $m_{\mathrm{w}} / m_{\mathrm{s}}$ gives an approximation to the medium effect, ${ }_{\mathrm{m}} \gamma$. In order to obtain values of ${ }_{m} \gamma$, the solubility of tris in a number of water-methanol mixtures has been measured at 15,25 , and $35{ }^{\circ} \mathrm{C}$ and the results are reported in this paper.

Equation (6) can be recast as follows:

$$
p_{\mathrm{s}} K-p_{\mathrm{w}} K=\log _{\mathrm{m}} \gamma_{\mathrm{B}}+2 \log _{\mathrm{m}} \gamma_{\mathrm{HCl}}-2 \log _{\mathrm{m}} \gamma_{\mathrm{B} \cdot \mathrm{HCl}}
$$

The terms on the left and the first term on the right are obtained from measurements to be described later in this paper. The term in ${ }_{\mathrm{m}} \gamma_{\mathrm{HCl}}$ corresponds to the free energy change in the transfer of hydrochloric acid from water to a water-methanol mixture and can be obtained from the standard emf of the cell with hydrogen and silver-silver chloride electrodes in water and in the water-methanol mixtures, determined by emf measurements of solutions of hydrochloric acid:

\section{$\mathrm{Pt} ; \mathrm{H}_{2}, \mathrm{HCl}$ in water or water-methanol, $\mathrm{AgCl} ; \mathrm{Ag}$.}

Values of these standard electromotive forces have been tabulated [7]. Accordingly, the remaining term in eq $(12),{ }_{\mathrm{m}} \gamma_{\mathrm{B} \cdot \mathrm{HCl}}$, the medium effect for the transfer of tris hydrochloride from water to water-methanol mixtures can be calculated and compared with similar free energy changes for other salts.

\section{Experimental Procedures}

\subsection{Dissociation Constants}

The dissociation constant of the protonated form of tris was determined in $30,50,70$, and $90 \mathrm{wt}$ percent methanol at $25^{\circ} \mathrm{C}$ by potentiometric titration. The cell:

\section{Glass electrode; $\mathrm{HCl}(0.01 \mathrm{~m})$ in water-methanol,} $\mathrm{AgCl} ; \mathrm{Ag}$

was set up and its emf $\left(E_{1}\right)$ measured when the silversilver chloride electrode had come to equilibrium. A solution consisting of $(0.01 \mathrm{~m} \mathrm{HCl}+0.1 \mathrm{~m}$ tris $)$ in the same water-methanol mixture was then added in measured amounts and the emf $\left(E_{2}\right)$ measured after each addition. Under these conditions of constant chloride concentration and constant total ionic strength (but varying ratio of tris to tris hydrochloride), the electrode comes to equilibrium quickly $[8,9]$. Then,

$$
p_{\mathrm{s}} K=\left(E_{2}-E_{1}\right) / k+\log \frac{m_{\mathrm{BH}^{+}}}{0.01 m_{\mathrm{B}}}+\log \frac{{ }_{\mathrm{s}} \gamma_{\mathrm{BH}^{+}} \cdot{ }_{\mathrm{s}} \gamma_{\mathrm{Cl}^{-}}}{{ }_{\mathrm{s}} \gamma_{\mathrm{B}} \cdot{ }_{\mathrm{s}} \gamma_{\mathrm{H}^{+}}^{\prime} \cdot{ }_{\mathrm{s}} \gamma_{\mathrm{Cl}^{-}}^{\prime}}
$$

where $k=(R T \ln 10) / F$ and the primed quantities refer to the initial solution to which no tris had been added. A number of determinations of $p_{\mathrm{s}} K$ can be made, one corresponding to each addition of the $(\mathrm{HCl}+$ tris) solution. The last term of eq (13) should be negligible for solutions of these low ionic strengths and we can write:

$$
p K=\left(E_{2}-E_{1}\right) / k+\log m_{\mathrm{BH}^{+}} /\left(0.01 m_{\mathrm{B}}\right) .
$$

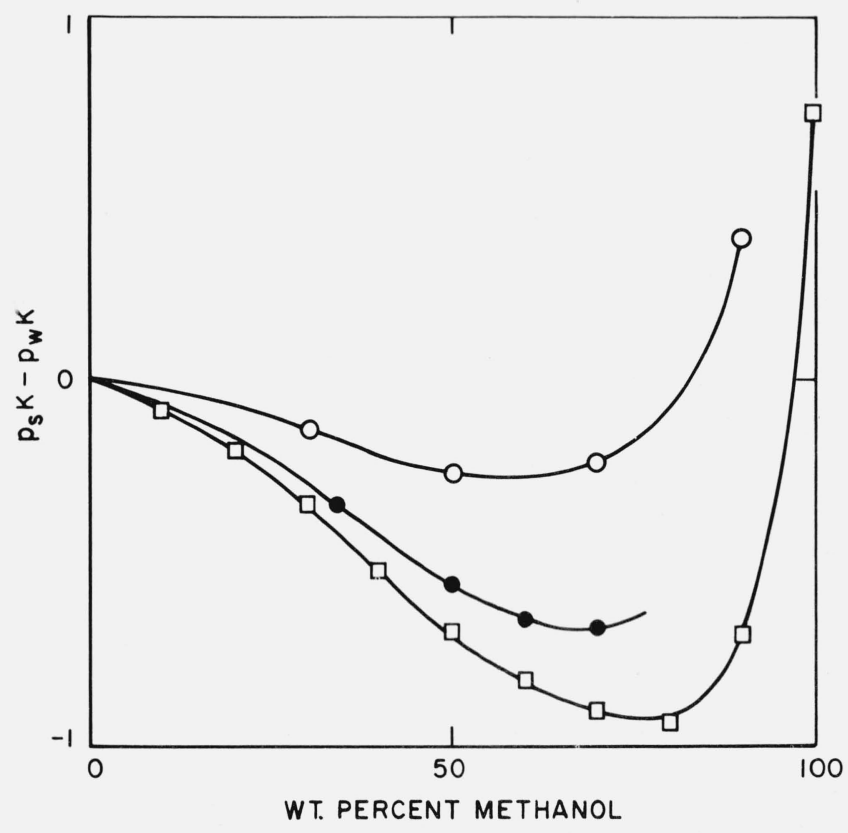

FIGURE 1. Difference between the $\mathrm{pK}$ value in water-methanol mixtures and in water $\left(\mathrm{p}_{s} \mathrm{~K}-\mathrm{p}_{w} \mathrm{~K}\right)$, for three acids.

o, Protonated form of tris(hydroxymethyl)aminomethane.

-, Ammonium ion.

$\square$, o-Chloroanilinium ion. 
This neglect of the activity coefficient term in eq (13) appears justifiable because, omitting this term, we find $p_{\mathrm{s}} K=7.825$ in 50 percent methanol. This value compares well with $p_{\mathrm{s}} K=7.818$ obtained earlier [3] using an emf method in which the activity coefficient term was eliminated by extrapolating the data to zero ionic strength.

The results of these potentiometric titrations are given in table 1 . They are compared, in figure 1 , with similar data for the ammonium ion [10] and the $o$-chloroanilinium ion [11]. It is apparent that the effect of solvent composition on $p_{\mathrm{s}} K$ is specific to each acid, but there is a general resemblance between the three curves insofar as the effect of adding methanol to the solvent medium is concerned. Addition of methanol first reduces the value of $p_{\mathrm{s}} K$. A minimum is reached between 60 and 80 percent methanol, after which $p_{\mathrm{s}} K$ rises to high values when the methanol content is large. There is evidence, for two of the acids, that the value of $p_{\mathrm{s}} K$ in solvents of high methanol content can exceed the $p K$ value in water; this is probably true also for the ammonium ion.

TABLE 1. Values of $\mathrm{p}_{s} \mathrm{~K}$ for the dissociation of the protonated form of tris(hydroxymethyl)aminomethane in water-methanol mixtures at $25{ }^{\circ} \mathrm{C}$

\begin{tabular}{c|c|c}
\hline \hline $\begin{array}{c}\text { Wt percent } \\
\text { methanol }\end{array}$ & $p_{\mathrm{s}} K$ & $p_{\mathrm{s}} K-p_{\mathrm{w}} K$ \\
\hline 0 & $\mathrm{a}(8.072)$ & $\ldots \ldots \ldots \ldots \ldots \ldots \ldots \ldots \ldots \ldots \ldots \ldots \ldots \ldots \ldots \ldots \ldots \ldots$ \\
30 & 7.940 & -.132 \\
50 & 7.825 & -.247 \\
70 & 7.855 & +.390 \\
90 & 8.462 & \\
\hline
\end{tabular}

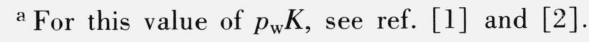

\subsection{Solubility}

Tris is a very soluble substance which readily supersaturates; moreover, its solubility is highly temperature-sensitive. Solubility measurements were, therefore, made in a constant temperature bath. The solutions were shaken at frequent intervals, but vigorous shaking was avoided. The solutions were analyzed by acidimetric titration at intervals of $24 \mathrm{hr}$.

TABLE 2. Solubility of tris(hydroxymethyl)aminomethane in watermethanol mixtures at 15,25 , and $35^{\circ} \mathrm{C}$

\begin{tabular}{|c|c|c|c|c|c|c|}
\hline \multirow{2}{*}{$\begin{array}{c}\text { Wt per- } \\
\text { cent } \\
\text { meth- } \\
\text { anol }\end{array}$} & \multicolumn{2}{|c|}{$15^{\circ} \mathrm{C}$} & \multicolumn{2}{|c|}{$25^{\circ} \mathrm{C}$} & \multicolumn{2}{|c|}{$35^{\circ} \mathrm{C}$} \\
\hline & $\mathrm{S}$ & $\sigma$ & S & $\sigma$ & S & $\sigma$ \\
\hline 0 & 4.593 & 0.001 & 5.780 & 0.008 & 7.261 & 0.004 \\
\hline 10 & 3.940 & .001 & 5.092 & .003 & 6.550 & .010 \\
\hline 20 & 3.363 & .002 & 4.450 & .010 & 5.827 & .003 \\
\hline 30 & 2.845 & .004 & 3.821 & .027 & 5.087 & .003 \\
\hline 40 & 2.382 & .004 & 3.223 & .027 & 4.366 & .003 \\
\hline 50 & 1.920 & .005 & 2.622 & .002 & 3.610 & .004 \\
\hline 60 & 1.455 & .001 & 2.009 & .011 & 2.813 & .001 \\
\hline 70 & 1.022 & .001 & 1.440 & .003 & 2.503 & .006 \\
\hline 80 & 0.6727 & .0007 & 0.9359 & .0007 & 1.356 & .008 \\
\hline 90 & .3700 & .0003 & .5368 & .0006 & 0.8443 & .0021 \\
\hline 100 & .2186 & .0001 & .2918 & .0007 & .4266 & .0007 \\
\hline
\end{tabular}

$\mathrm{S}=$ solubility in moles per kilogram of solvent. $\sigma=$ standard deviation.
TABLE 3. Medium effects and free energy changes in the transfer of tris(hydroxymethyl)aminomethane from water to water-methanol solvents

\begin{tabular}{c|c|c|c|c|c|c}
\hline \hline $\begin{array}{c}\text { Wt per- } \\
\text { cent } \\
\text { meth- } \\
\text { anol }\end{array}$ & \multicolumn{2}{|c|}{$15{ }^{\circ} \mathrm{C}$} & \multicolumn{2}{|c|}{$25{ }^{\circ} \mathrm{C}$} & \multicolumn{2}{c}{$3{ }^{\circ} \mathrm{C}$} \\
\hline & \multicolumn{2}{|c|}{} & \multicolumn{2}{|c|}{} \\
& $\log _{\mathrm{m}} \gamma_{\mathrm{B}}$ & $\Delta_{\mathrm{m}} G_{\mathrm{B}}^{\circ}$ & $\log _{\mathrm{m}} \gamma_{\mathrm{B}}$ & $\Delta_{\mathrm{m}} G_{\mathrm{B}}^{\circ}$ & $\log _{\mathrm{m}} \gamma_{\mathrm{B}}$ & $\Delta_{\mathrm{m}} G_{\mathrm{B}}^{\circ}$ \\
\hline & & & & & & \\
10 & $0.066_{7}$ & $0.36_{8}$ & $0.055_{0}$ & $0.31_{4}$ & $0.044_{5}$ & $0.26_{3}$ \\
20 & .135 & .745 & .114 & $.65_{1}$ & $.095_{5}$ & $.56_{3}$ \\
30 & .208 & 1.15 & .180 & 1.03 & .154 & $.90_{9}$ \\
40 & .285 & 1.57 & .254 & 1.45 & .221 & 1.30 \\
50 & .379 & 2.09 & .343 & 1.96 & .303 & 1.79 \\
60 & .499 & 2.75 & .459 & 2.62 & .412 & 2.43 \\
70 & .653 & 3.60 & .604 & 3.45 & .549 & 3.24 \\
80 & .834 & 4.60 & .791 & 4.52 & .729 & 4.30 \\
90 & 1.094 & 6.04 & 1.032 & 5.89 & .935 & 5.52 \\
100 & 1.322 & 7.29 & 1.297 & 7.40 & 1.231 & 7.26 \\
\hline
\end{tabular}

Values of $\Delta_{\mathrm{m}} G_{\mathrm{B}}^{\circ}$ are expressed in $\mathrm{kJ} \mathrm{mol}^{-1}$.

The solutions were assumed to be in equilibrium with the solid phase if no change in concentration was found over a period of $72 \mathrm{hr}$. The equilibration time was between two and three weeks.

Table 2 gives the solubilities (in moles per kilogram of solvent) at 15,25 , and $35{ }^{\circ} \mathrm{C}$. Table 3 records the medium effect, $\log _{\mathrm{m}} \gamma_{\mathrm{B}}$, calculated from these solubility values with the aid of the equation:

$$
\log _{\mathrm{m}} \gamma_{\mathrm{B}} \approx \log m_{\mathrm{w}} / m_{\mathrm{s}}
$$

and also the corresponding free energy changes, $\Delta_{\mathrm{m}} C_{\mathrm{B}}^{\circ}=R T \ln _{\mathrm{m}} \gamma_{\mathrm{B}}$. From the temperature coefficient of the free energy change, it is possible to calculate the enthalpy and entropy changes accompanying the transfer process. Values of $\Delta_{\mathrm{m}} H_{\mathrm{B}}^{\circ}$ and $\Delta_{\mathrm{m}} S_{\mathrm{B}}^{\circ}$ are given in table 4 . These were calculated by assuming that over this $20{ }^{\circ} \mathrm{C}$ temperature range:

$$
\Delta_{\mathrm{m}} G_{\mathrm{B}}^{\circ}=A+B T+C T^{2} .
$$

TABLE 4. Enthalpy and entropy changes in the transfer of tris(hydroxymethyl)aminomethane from water to water-methanol solvents at $25{ }^{\circ} \mathrm{C}$

\begin{tabular}{c|c|c}
\hline \hline $\begin{array}{c}\text { Wt percent } \\
\text { methanol }\end{array}$ & $\Delta_{\mathrm{m}} H_{\mathrm{B}}^{\circ}$ & $\Delta_{\mathrm{m}} S_{\mathrm{B}}^{\circ}$ \\
\hline & & \\
20 & 1.9 & 5 \\
30 & 3.4 & 9 \\
40 & 4.6 & 12 \\
50 & 5.5 & 14 \\
60 & 6.5 & 15 \\
70 & 7.4 & 16 \\
80 & 8.8 & 18 \\
90 & 9.0 & 15 \\
100 & 13.6 & 26 \\
& 7.9 & 2 \\
\hline
\end{tabular}

$\Delta_{\mathrm{m}} H_{\mathrm{B}}^{\circ}$ is given in $\mathrm{kJ} \mathrm{mol}^{-1}$ ard $\Delta_{\mathrm{m}} S_{\mathrm{B}}^{\circ}$ in $\mathrm{J} \mathrm{deg}^{-1} \mathrm{~mol}^{-1}$.

Then, it can be shown that:

$$
\Delta_{\mathrm{m}} H_{\mathrm{B}}^{\circ}=g_{2}-0.05\left(g_{3}-g_{1}\right) T_{0}
$$

and

$$
\Delta_{\mathrm{m}} S_{\mathrm{B}}^{\circ}=0.05\left(g_{1}-g_{3}\right),
$$


for the enthalpy and entropy changes at the middle temperature $\left(T_{0}=298.15^{\circ} \mathrm{K}\right)$, where $g_{1}, g_{2}$, and $g_{3}$ are the values of $\Delta_{\mathrm{m}} G_{\mathrm{B}}^{\circ}$ at 15,25 , and $35^{\circ} \mathrm{C}$, respectively.

\section{Discussion}

We now have the three quantities necessary to calculate $\log _{\mathrm{m}} \gamma_{\mathrm{B} \cdot \mathrm{HCl}}$ by means of eq (12). Values of $\left(p_{\mathrm{s}} K-p_{\mathrm{w}} K\right)$ are given in table $1, \log _{\mathrm{m}} \gamma_{\mathrm{B}}$ appears in table 3 , and $2 \log _{\mathrm{m}} \gamma_{\mathrm{HCl}}$ is calculated from the standard potentials of cells containing hydrochloric acid $[7,12]$. All of these values are collected in table 5 along with $\log _{\mathrm{m}} \gamma_{\mathrm{B} \cdot \mathrm{HCl}}$ calculated with the aid of eq (12). The latter have also been expressed in terms of the free energy of transfer of tris hydrochloride from water to water-methanol. Table 5 also contains values of $\log _{\mathrm{m}} \gamma_{\mathrm{LiCl}}$ for the transfer of lithium chloride from water to water-methanol [13]. It can be seen, especially if the data are plotted as in figure 2, that the energies of transfer between water and water-methanol solvents of the same composition are similar for lithium chloride and for tris hydrochloride.

TABLE 5. Medium effects involved in the dissociation of protonated tris(hydroxymethyl)aminomethane in water-methanol solvents at $25^{\circ} \mathrm{C}$

\begin{tabular}{|c|c|c|c|c|}
\hline $\begin{array}{l}\text { Wt percent } \\
\text { methanol }\end{array}$ & 30 & 50 & 70 & 90 \\
\hline 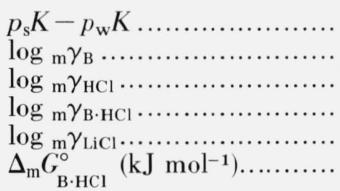 & $\begin{array}{r}-0.132 \\
.180 \\
.162 \\
.319 \\
.361 \\
3.64\end{array}$ & $\begin{array}{r}-0.247 \\
.343 \\
.268 \\
.563 \\
.620 \\
6.43\end{array}$ & $\begin{array}{r}-0.217 \\
.604 \\
.456 \\
.867 \\
.936 \\
9.90\end{array}$ & $\begin{array}{r}+0.390 \\
1.032 \\
0.920 \\
1.240 \\
1.369 \\
14.16\end{array}$ \\
\hline
\end{tabular}

The present picture of the transfer process is different from that discussed earlier [3], as shown by the following résumé of the free energies of transfer (in $\mathrm{kJ} \mathrm{mol}^{-1}$ ) from water to 50 percent methanol:

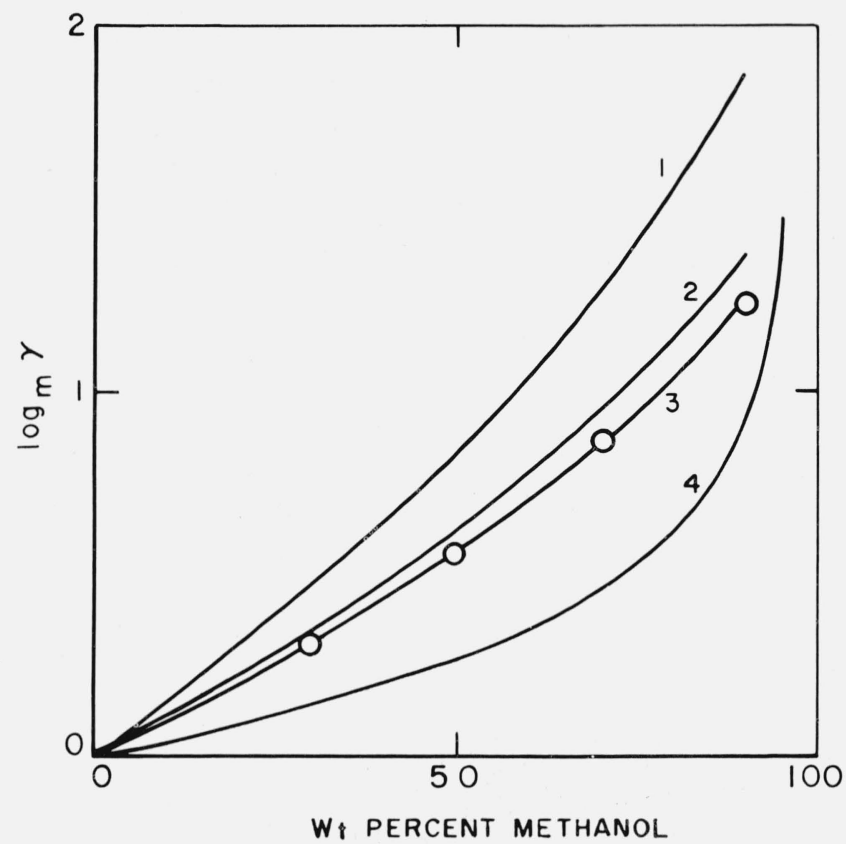

FIGURE 2. Medium effects for the transfer of electrolytes from water to water-methanol solvents. $1 \mathrm{NaCl}, \mathrm{L}$ LiCl,
3 Tris $\cdot \mathrm{HCl}, \quad 4 \mathrm{HCl}$.

The small difference between the two values given for the energy of process (i) arises from the difference between the values of $p_{\mathrm{s}} K$ recorded in table 1 and that given earlier [3]. As already indicated, the calculations of the earlier study gave only the free energy of transfer of the solvated hydrogen ion $\left(1.24 \mathrm{~kJ} \mathrm{~mol}^{-1}\right)$ and that of the $\mathrm{B} \cdot \mathrm{H}^{+}$ion $\left(0.87 \mathrm{~kJ} \mathrm{~mol}^{-1}\right)$ for the transfer from water to 50 percent methanol. Therefore, for the comparisons shown above we have also used eq (7) to calculate a value of $1.91 \mathrm{~kJ} \mathrm{~mol}^{-1}$ for the transfer of a mole of chloride ion from water to 50 percent methanol, assuming a radius of $1.81 \AA$ for this ion. The calculated values for the processes (ii) and (iii) accordingly become -2.78 and $3.15 \mathrm{~kJ} \mathrm{~mol}^{-1}$.

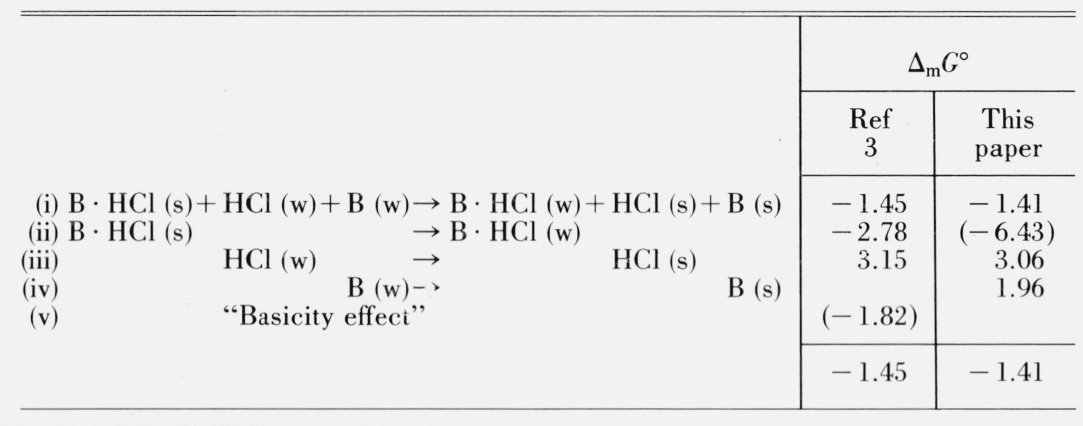

Although specific interactions and selective solvation might be expected to have a stronger influence in solutions of hydrochloric acid than in solutions of tris hydrochloride, it is interesting to note that the transfer free energy for hydrochloric acid computed from purely electrostatic considerations is close to the experimental value given in the last column. while the differences for tris hydrochloride are considerable. In the earlier work, no attempt was made to estimate the free energy of process (iv). Instead, the discrepancy between the known value for process (i) and the sum of the calculated energies of processes (ii) and (iii) was attributed to a basicity effect (v), considered to be superimposed on the electrostatic energies, calcu- 
lated from the Born model, eq (7). A more detailed analysis based on the concept of a variable dielectric constant in the vicinity of the ion affects the numerical values of the transfer energies but does not change the conclusions [3].

In this paper, however, we have described how transfer energies for tris can be determined experimentally by means of solubility measurements. The value of $1.96 \mathrm{~kJ} \mathrm{~mol}^{-1}$ in the above tabulation, therefore, is an experimental quantity. Furthermore, the energy of transfer of hydrochloric acid, $3.06 \mathrm{~kJ} \mathrm{~mol}^{-1}$, has been derived from emf measurements. The approximate agreement with the value of $3.15 \mathrm{~kJ} \mathrm{~mol}^{-1}$ calculated by means of the Born equation, assuming a reasonable value of the ionic radius, suggests that the electrostatic effect is the main one in this instance.

The value of $-6.43 \mathrm{~kJ} \mathrm{~mol}^{-1}$ for the transfer energy of tris hydrochloride has not been derived by independent means but is based on the experimental values for processes (i), (iii), and (iv). The pertinent relationship among these quantities is set forth in eq (12). The discrepancy between the two values for the tris. $\mathrm{H}^{+}$ion

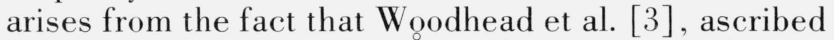
a reasonable value of $4 \AA$ to the radius of the tris cation and assumed that the electrostatic effect, as calculated by means of eq (7), gives a complete account of the transfer process. It is now found that the energy of transfer of tris hydrochloride from water to 50 percent methanol is $3.7 \mathrm{~kJ} \mathrm{~mol}^{-1}$ larger than that so calculated.

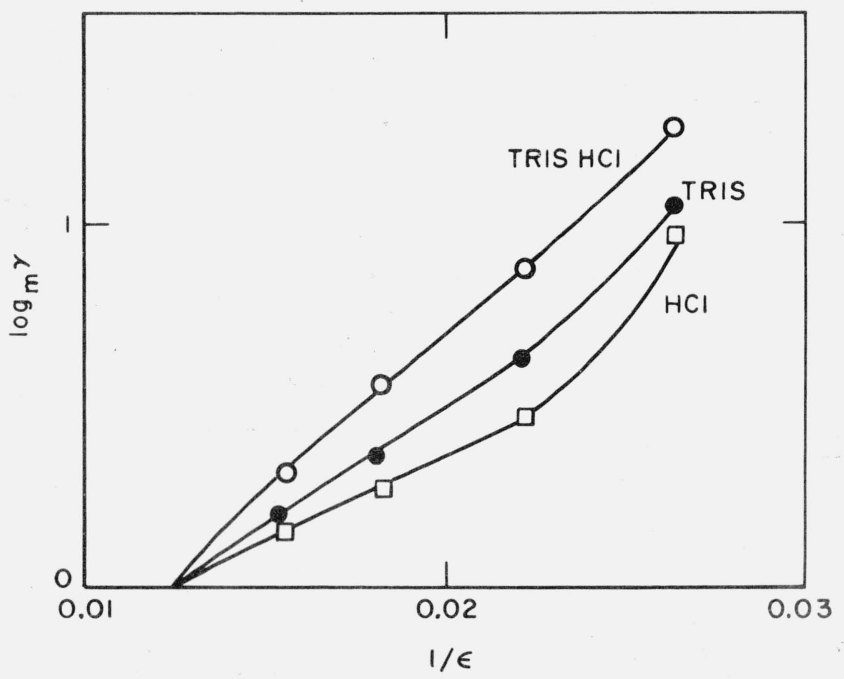

FIGURE 3. Medium effects for the transfer from water to watermethanol solvents, as a function of the reciprocal of the dielectric constant of the medium.

o. Tris(hydroxymethyl)aminomethane hydrochloride.

-, Tris(hydroxymethyl)aminomethane.

$\square$, Hydrochloric acid.

Figure 3 is a plot of $\log _{\mathrm{m}} \gamma$ for three transfer processes from water to water-methanol against the reciprocal of the dielectric constant of the solvent. According to eq (7), two of these should be straight lines; it is curious that the best approximation to a straight line is found for the nonelectrolyte, tris. Nevertheless, up to a solvent composition of 70 percent methanol, the plots for hydrochloric acid and tris hydrochloride are almost linear and therefore satisfy one requirement of eq (7). According to this equation, however, if we take $1.91 \mathrm{~kJ} \mathrm{~mol}^{-1}$ for the energy of transfer of the chloride ion from water to 50 percent methanol, the radius of the cation is given by the equation:

$$
r_{+}=\frac{N e^{2}}{2 \Delta_{\mathrm{m}} G_{+}^{\circ}}\left(\frac{1}{\epsilon_{\mathrm{s}}}-\frac{1}{\epsilon_{\mathrm{w}}}\right)
$$

or

$$
r_{+}=3.466\left(\Delta_{\mathrm{m}} G_{+}^{\circ}\right)^{-1}
$$

if $r_{+}$is expressed in $\AA$ and $\Delta_{\mathrm{m}} C_{+}^{\circ}$ in $\mathrm{kJ} \mathrm{mol}^{-1}$, and the transfer process occurs between water $\left(\epsilon_{\mathrm{w}}=78.3\right)$ and 50 percent methanol $\left(\epsilon_{\mathrm{s}}=56.3\right)$.

Akerlof [13] has determined $\log _{m} \gamma$ for the transfer of potassium chloride, sodium chloride, and lithium chloride and, if his data for the transfer of these salts from water to 50 percent methanol are used, values of $r_{+}=0.40,0.44$, and $0.67 \AA$ are obtained for the potassium, sodium, and lithium cations, respectively, assuming a radius of $1.81 \AA$ for the chloride ion. Similarly, from the values of $\Delta_{\mathrm{m}} G^{\circ}$ for tris hydrochloride and hydrochloric acid, we find $r_{+}=0.77$ and $3.02 \AA$ for protonated tris and hydrogen ions, respectively. Of these five cationic radii, only one, that of the hydrogen ion, is reasonable; the others are much too small. The anomaly is all the more curious because there is every reason to believe that the Debye-Hückel theory gives the correct values of the activity coefficients ${ }_{s} \gamma$ in 50 percent methanol just as it does for water as solvent, provided that the macroscopic dielectric constant is used in the Debye-Hückel equation and a reasonable value of the ion-size parameter is introduced. The use of the macroscopic dielectric constant, therefore, explains the concentration dependence of the activity coefficient in both solvent media but fails to account for the energy of transfer from one solvent to the other.

The standard state used in this discussion is that for the molal scale of concentration, both in water and in water-methanol. It is possible that the standard state on the mole-fraction scale would be a better choice. Equations for the conversion from one scale to the other can be found elsewhere [14]; the energy of transfer of the hydrogen ion from water to 50 percent methanol is lower by $0.61 \mathrm{~kJ} \mathrm{~mol}^{-1}$ on the mole-fraction scale than on the molality scale, and the same is true of the chloride ion. Thus the energy of transfer of hydrochloric acid is $1.84 \mathrm{~kJ} \mathrm{~mol}^{-1}$ on the mole-fraction scale and $3.06 \mathrm{~kJ} \mathrm{~mol}^{-1}$ on the molality scale. Nevertheless, the adoption of the mole-fraction scale does not lead to a more reasonable set of ionic radii.

It is clear that there are difficulties in reconciling the transfer processes with a purely electrostatic theory. Nevertheless, if the experimental finding that the transfer process for tris hydrochloride is about equal in magnitude to that for lithium chloride is accepted, the diminution in the value of $p K$ of the tris cation on addition of methanol (except for those solutions very 
solvent can be measured relative to the hypothetical standard state in that solvent:

$$
G={ }_{\mathrm{s}} G^{\circ}+R T \ln { }_{\mathrm{s}}^{s} \gamma \cdot m_{\mathrm{s}},
$$

where $m_{\mathrm{s}}$ is the molality of the solution, ${ }_{\mathrm{s}} G^{\circ}$ is the free energy of the solute in the standard state in this solvent mixture, and $s \gamma$ is the activity coefficient of the solute referred to the standard state in this solvent.

The free energy could, however, be referred to the hypothetical standard state in water as solvent:

$$
G={ }_{\mathrm{w}} G^{\circ}+R T \ln \underset{\mathrm{w}}{\stackrel{s}{\gamma}} \gamma \cdot m_{\mathrm{s}},
$$

where ${ }_{\mathrm{w}} G^{\circ}$ is the free energy of the solute in the standard state in water and ${ }_{\mathrm{w}}^{s} \gamma$ is the activity coefficient of the solute in the mixed solution (s) but referred to the standard state in water $(\mathrm{w})$.

We now consider the limit when $m_{\mathrm{s}} \rightarrow 0$ and ${ }_{\mathrm{s}}^{s} \gamma \rightarrow 1$. Under these circumstances,

$$
{ }_{\mathrm{s}} G^{\circ}-{ }_{\mathrm{w}} G^{\circ}=R T \operatorname{Lim}_{m_{\mathrm{s}} \rightarrow 0} \ln { }_{\mathrm{w}}^{s} \gamma .
$$

This is an expression for the free energy change in transferring the solute from water to the mixed solvent in the limit of extreme dilution when the concentration effects on the free energy change are absent. It is, therefore, the free energy change for the transfer from one hypothetical standard state to another, where also concentration effects are absent. Consequently,

$$
\operatorname{Lim}_{m_{\mathrm{s}} \rightarrow 0} \ln _{\mathrm{w}}^{s} \gamma=\ln _{\mathrm{m}} \gamma
$$

from which follows the important relation:

$$
{ }_{\mathrm{w}}^{s} \gamma={ }_{\mathrm{m}} \gamma \cdot{ }_{\mathrm{s}}^{s} \gamma \text {. }
$$

Equation (24) is sometimes abbreviated to:

$$
{ }_{\mathrm{w}} \gamma={ }_{\mathrm{m}} \gamma \cdot{ }_{\mathrm{s}} \gamma,
$$

but when this is done care should be taken to note that here ${ }_{w} \gamma$ is an activity coefficient in the mixed solvent relative to the standard state in water, whereas in eq (1) w $\gamma$ designates an activity coefficient in aqueous solution relative to the standard state in water.

We next consider the equilibrium between a solid and its saturated solution. The condition for equilibrium between a solid and its saturated solution in a mixed solvent is:

$$
G(\text { solid })={ }_{\mathrm{w}} G^{\circ}+R T \ln { }_{\mathrm{m}} \gamma \cdot{ }_{\mathrm{s}}^{s} \gamma \cdot m_{\mathrm{s}}
$$

and the condition for equilibrium between the solid and its saturated aqueous solution is:

$$
G(\text { solid })={ }_{\mathrm{w}} G^{\circ}+R T \ln \underset{\mathrm{w}}{w} \gamma \cdot m_{\mathrm{w}} .
$$

Hence,

$$
\ln m_{\mathrm{w}} / m_{\mathrm{s}}=\ln { }_{\mathrm{m}} \gamma+\ln { }_{\mathrm{s}}^{s} \gamma /{ }_{\mathrm{w}}^{w} \gamma,
$$

which is sometimes abbreviated to:

$$
\ln m_{\mathrm{w}} / m_{\mathrm{s}}=\ln { }_{\mathrm{m}} \gamma+\ln _{\mathrm{s}} \gamma /{ }_{\mathrm{w}} \gamma,
$$

which is eq (11). It should be noted that ${ }_{w} \gamma$ is now used, as in the body of the text, to denote an activity coefficient in aqueous solution relative to the standard state in water.

\section{References}

[1] R. G. Bates and H. B. Hetzer, J. Phys. Chem. 65, 667 (1961).

[2] S. P. Datta, A. K. Grzybowski, and B. A. Wilson, J. Chem. Soc. (London), 792 (1963).

[3] M. Woodhead, M. Paabo, R. A. Robinson, and R. G. Bates, J. Res. NBS 69A (Phys. and Chem.) No. 3, 263 (1965).

[4] M. Born, Z. Physik 1, 45, 221 (1920).

[5] L G. Hepler, Aust. J. Chem. 17, 587 (1964).

[6] R. A. Robinson and V. E. Bower, J. Chem. Eng. Data 10, 246 (1965).

[7] R. G. Bates and R. A. Robinson, Acid-base behavior in methanolwater solvents, in Chemical physics of ionic solutions, B. E. Conway and R. G. Barradas, Eds (John Wiley \& Sons, Inc., New York, N.Y., 1966).

[8] R. G. Bates, G. L. Siegel, and S. F. Acree, J. Res. NBS 30, 347 (1943).

[9] J. M. Stokes and R. H. Stokes, J. Phys. Chem. 67, 2442 (1963).

[10] M. Paabo, R. G. Bates, and R. A. Robinson, J. Phys. Chem. 70, 247 (1966).

[11] E. E. Sager, R. A. Robinson, and R. G. Bates, J. Res. NBS 68A (Phys. and Chem.), No. 3, 305 (1964).

[12] I. T. Oiwa, Sci. Rpt. Tohoku Univ., Ser. 1, 41, 47 (1957).

[13] G. Ákerlöf, J. Am. Chem. Soc. 52, 2353 (1930).

[14] R. A. Robinson and R. H. Stokes, Electrolyte solutions, pp. 39 and 352, revised edition (Butterworths Scientific Publications, London, 1965).

[15] D. H. Everett and W. F. K. Wynne-Jones, Trans. Faraday Soc. 48, 531 (1952).

[16] F. E. C. Scheffer and H. J. DeWijs, Rec. Trav. Chim. 44, 655 (1925).

[17] W. Y. Wen, S. Saito, and C. M. Lee, J. Phys. Chem. 70, 1244 (1966).

[18] W. Y. Wen and S. Saito, J. Phys. Chem. 69, 3569 (1965).

(Paper 72A2-489) 